\title{
EDUCAÇÃO E TECNOLOGIA: CONTRADIÇÕES E SUPERAÇÕES NO CAMPO DA POLÍTICA EDUCACIONAL
}

\author{
J. L. da SILVA e E. L. PAULY \\ Centro Universitário La Salle - UNILASALLE Canoas/RS \\ Submetido em 03/06/2016 - Aceito em 03/11/2016
}

DOI: $10.15628 /$ holos.2016.3106

\section{RESUMO}

$\mathrm{O}$ artigo reflete sobre a contradição existente na educação brasileira entre os indicadores que apontam fragilidades e, ao mesmo tempo, sinalizam para os ganhos com maior investimento em educação. Perpassa pelo contraste entre a baixa qualidade da educação básica, os possíveis impactos da tecnologia na educação e as possibilidades de uma melhor relação entre professores e alunos. Através da análise da política educacional, o artigo aponta para uma aparente dificuldade de diálogo entre a forma de produzir conhecimento na comunidade escolar e a forma de produzir conhecimento nas comunidades desenvolvedoras de Software Livre. O artigo estruturase em duas partes, na primeira desenvolve as contradições entre a educação e a tecnologia; na segunda apresenta uma experiência docente realizada em um curso do PRONATEC com o objetivo de pensar na possibilidade de organizar um caminho que aproxime o modo de fazer dos tecnólogos do modo de fazer dos professores.

PALAVRAS-CHAVE: Software Livre, Tecnologia, Educação Básica, Pronatec

\section{EDUCATION AND TECHNOLOGY : CONTRADICTIONS AND OVERRUNS IN POLICY EDUCATIONAL FIELD}

\begin{abstract}
The article reflects on the contradiction in the Brazilian education among the indicators pointing weaknesses and at the same time, signal to the gains from increased investment in education. Moves through the contrast between the low quality of basic education, the possible impact of technology in education and the possibility of a better relationship between teachers and students. Through the analysis of educational policy, the article points to an apparent difficulty of dialogue between the
\end{abstract} and how to produce knowledge in the developers of Free Software communities. The article is divided into two parts, the first develops the contradictions between education and technology; the second shows the teaching experience held in a travel PRONATEC in order to consider the possibility of organizing a way that approximates how to do the technologists way of making teachers .

KEYWORDS: Free Software, Technology, Basic Education, Pronatec 


\section{INTRODUÇÃO}

No Brasil, a educação se aproximou das comunidades de software livre na medida em que a política educacional orienta para o uso desta modalidade tecnológica nas escolas administradas pelo poder público. Essa parceria possibilitou uma relação interdisciplinar, ainda que turbulenta, entre escolas e desenvolvedores de Software Livre promovendo uma série de reflexões sobre as possíveis contribuições da tecnologia na educação e vice versa.

Particularmente, têm-se destacado nessa questão os movimentos voltados para adoção de softwares não-proprietários, conhecidos mais fortemente a partir do crescimento do movimento GNU/Linux em todo o mundo. Para a educação, libertar-se dos softwares proprietários é um grande desafio, uma vez que a possibilidade de independência no acesso aos códigos fontes está intimamente associada às inúmeras possibilidades de independência de fornecedores centralizados que dominam o mercado, possibilitando a ampliação de uma rede de produção colaborativa, dimensão fundamental para a educação. (Pretto; Pinto, 2006, p. 21-22)

Estando as comunidades de software livre fundamentadas na perspectiva da colaboração, ao se aproximarem das escolas do ensino básico ocorreu reflexões sobre o papel da educação tendo como principal interesse um questionamento acerca da possibilidade de uma educação colaborativa mediada pelas tecnologias, em especial, em contextos onde a tecnocracia e o individualismo se tornaram uma forte referência cultural. A perspectiva colaborativa em comunidades de produção tecnológica pode ser entendida como um conjunto de ações direcionadas por um senso de comunidade, onde a propagação de ideias e conhecimentos assumem um caráter de ato público. Nas comunidades de Software Livre a ideia de colaboração consiste, entre outras coisas, na soma de esforços para promover o livre acesso ao conhecimento, uso e desenvolvimento tecnológico, onde é tornada pública a maneira como uma dada tecnologia é construída. No entanto, no ambiente educacional o uso de tecnologias ainda é um tema que requer clareza e ampliação do senso crítico, dificultando em alguns casos, a relação entre as comunidades de produção tecnológica e a comunidade escolar.

\section{EDUCAÇÃO E TECNOLOGIA: CONTRADIÇÕES}

O sistema educacional brasileiro enfrenta dificuldades quando observados alguns indicadores, como o Índice de Desenvolvimento Humano (IDH), organizado pelo Programa das Nações Unidas para o Desenvolvimento (PNUD) que, em 2012, classificou o Brasil em terceiro lugar com a maior taxa de evasão escolar numa lista de cem países. O censo do Instituto Brasileiro de Geografia e Estatística (IBGE) de 2010 registrou a média de $49.3 \%$ de brasileiros maiores de 25 anos sem a conclusão do ensino médio. O Índice de Desenvolvimento da Educação Básica (IDEB), organizado pelo Instituto Nacional de Estudos e Pesquisas Educacionais Anísio Teixeira (INEP) em uma escala de 10 pontos classificou em 2012 a qualidade da educação do ensino médio com 3.7 pontos (UOL, 2013). A Avaliação Nacional do Rendimento Escolar (ANRESC) e a Avaliação Nacional da Educação Básica (ANEB) instrumentos que compõem o Sistema de Avaliação da Educação Básica (SAEB), em 2011, apontou que a disciplina de 
matemática sinalizou um desempenho favorável para aproximadamente $10.1 \%$ dos alunos do ensino médio. Na ocasião desse resultado circulou na imprensa que "quase $90 \%$ dos alunos que concluem o ensino médio não sabem matemática". ${ }^{1}$

Por outro lado, a educação apresenta, nos últimos anos, vários aspectos positivos como os investimentos no programa Ciência sem Fronteiras, a distribuição de tablets nas escolas, vários cursos gratuitos de capacitação para professores da rede pública, distribuição de bolsas de estudo e campanhas com aporte financeiro para o desenvolvimento dos sistemas educacionais, maior facilidade de acesso da população a cursos técnicos e de graduação através de programas de financiamento estudantil, bem como, o aumento do número de instituições de ensino (FNDE, 2015). Uma maior evolução parece ter ocorrido no acesso aos cursos de graduação, evento divulgado em veículos de comunicação de massa sob o titulo "Número de brasileiros com graduação cresce 109,83\% em 10 anos" (BRASIL, 2012). Também o desempenho escolar ocupou destaque nas notícias sob o título "Brasil evolui, mas segue nas últimas posições em ranking de educação" (G1, 2013), sinalizando que o país embora esteja avançando positivamente nos últimos anos em questões sobre educação, apresenta desempenho insuficiente quando comparado a outros países.

Os indicadores podem ser analisados de forma polarizada. Sob uma perspectiva histórica, compara-se a educação atual com a passada, destacando resultados positivos e seu crescimento. Sob uma perspectiva global, comparando o desempenho do país com o de outras nações, o Brasil está em um dos últimos lugares na classificação geral. A perspectiva histórica vê uma educação em expansão com problemas emergentes próprios desta evolução; já aqueles que dão ênfase aos resultados obtidos pelos indicadores internacionais, a percepção possível é de estagnação e crise. O raciocínio binário admite apenas um dos indicadores como verdadeiro, se existe crise não pode existir expansão, se existe expansão não pode existir crise. Nesse sentido a questão assume um caráter de oposição unilateral incapaz de contextualizar a complexa relação entre os fenômenos e seus indicadores.

Segundo diagnosticou Moraes (1997, p. 86) existem casos onde "a dificuldade de trabalhar dentro de uma visão sistêmica, com um enfoque de totalidade, tem ocasionado poucos avanços em direção à solução de alguns problemas educacionais". Esse tipo de postura que carece de contextualização abrangente, motivada por uma interpretação binária, é entendido como "raciocínio tecnológico" por Postman (1994), Bauman (2007), Baudrillard (1991), entre outros, sinalizando que uma parte dos problemas na educação e na sociedade pode ser consequência de um modelo de pensamento unilateral, binário.

Algumas dificuldades são diagnosticadas como produto da aceleração tecnológica que enfatiza o pensamento binário e sobrecarrega a escola de informações. Postman (1994, p. 62) defende que o computador é uma ameaça para a escola tradicional uma vez que essa tecnologia serve para convencer de que tal inovação representa progresso humano e social, enquanto reduz as comunidades a uma sociedade homogênea, trivializando tudo e todos, reduzindo conhecimento à mera informação e promovendo a substituição de valores sociais por egocentrismos. Em sociedades tecnológicas estruturadas pelo culto à tecnologia da informação,

\footnotetext{
${ }^{1}$ Matéria encontrada nos jornais, O povo de fortaleza em 07/03/2013, Globo.com em 06/03/2013, Caderno especial de Zero Hora sobre educação em 02/12/2012, Portal IG 23/02/2011 e 01/12/2010 além de várias reproduções pautadas nestas fontes em fóruns, blogs e sites nos últimos anos.

2 Matéria pautada em dados do IBGE e encontrada nos jornais Zero Hora em 03/05/2012, Portal UOL em 04/05/2012, Portal do MEC em 03/05/2012, Globo.com em 04/05/2012, além de varias reproduções em blogs, fóruns online e diversos outros meios de comunicação de massa.

${ }^{3}$ Matéria publicada no jornal Zero Hora em 04/12/2013, Globo.com em 03/12/2013, Portal R7.com em 04/12/2013, Portal UOL em 04/12/2013 além de diversos outros veículos de notícias online.
} 
os relacionamentos com a tecnologia podem ocorrer de forma alienante, tudo se torna uma questão de aplicação da técnica e se perde o entendimento das coisas, apenas se aceita a ordem estabelecida pelos especialistas, numa corrida frenética por informação. Existe especialista para tudo, "em criação das crianças, em educação, em como ser amável, em como fazer amor, em como influenciar pessoas, em como fazer amigos" (Postman, 1994, p. 95). Aos poucos, a necessidade de desenvolvimento individual do pensamento crítico e analítico foi substituída pela necessidade de acessar a informação do especialista.

Para cada crença, hábito ou tradição do velho mundo havia e ainda há uma alternativa tecnológica. Para a oração, a alternativa é a penicilina; para as raízes da família, a alternativa é a mobilidade; para a leitura, a alternativa é a televisão; para a restrição, a alternativa é a gratificação imediata; para o pecado, a alternativa é a psicoterapia; para a ideologia política a alternativa é o apelo popular estabelecido por meio da pesquisa científica de opinião. (Postman, 1994, p, 63).

Entendendo que a tecnologia influencia o pensamento, Postman denuncia a ameaça do computador como possibilidade de rendição da escola à proposta tecnológica, tornando-se unicamente formadora de especialistas, promovendo a exclusão da humanidade uma vez que "o computador exige soberania sobre todo o âmbito da experiência humana, e sustenta essa exigência demonstrando que 'pensa' melhor do que nós" (Postman, 1994, p. 117, grifo do autor). $\mathrm{O}$ autor entende que os problemas nas relações sociais estão no âmbito do reconhecimento da experiência humana enquanto formação moral, papel da escola tradicional. "Se famílias se desfazem, se crianças são maltratadas, se o crime aterroriza uma cidade, se a educação é impotente, isso não ocorre por falta de informação adequada" (Postman, 1994, p. 62). Reafirma a importância em resgatar o papel da escola tradicional como formadora do senso crítico e analítico para o esclarecimento sobre os efeitos tecnológicos apontando que "precisamos de estudantes que compreendam as relações entre nossas técnicas e nossos mundos social e psíquico, de modo que possam iniciar conversas informadas sobre a onde a tecnologia nos está levando e como" (Postman, 1994, p. 203).

Esta perspectiva também é defendida por Bauman ainda que de modo mais ameno, entendendo a tecnologia como um sistema fechado, autorreferente, que faz prevalecer a simplificação da técnica para tudo. "quanto mais problemas gera a tecnologia, tanto mais de tecnologia se precisa" (Bauman, 1997, p. 213). Como tudo é simplificado e resolvido pela técnica, não existe espaço para tratar questões ambíguas e complexas, o "eu" do homem moderno se constitui cada vez mais mediado por percepções fragmentadas de mundo. Este "eu" fragmentado não se confronta com a totalidade do mundo, do outro ou de si mesmo, proporcionando um comportamento individualista e irresponsável para com a sociedade e a natureza, impossibilitando uma possível manifestação do "eu" moral.

Segundo Bauman, a escola tradicional difundia a educação como algo para toda a vida e o conhecimento continha seu valor de forma proporcional à sua duração, onde o saber da experiência adquirido ao longo do tempo ganhava destaque. Na atualidade, o sistema educacional recebeu um duro golpe uma vez que os valores sociais se inverteram. Enquanto a tradição valoriza a rotina e o conhecimento duradouro, pautado na busca pelos fundamentos; na 
sociedade atual, influenciada pela tecnologia, prevalece a importância da flexibilidade e de cursos rápidos que sejam úteis para o momento fugaz do mercado de trabalho.

No torvelinho da mudança, o conhecimento serve para uso imediato e único; conhecimento pronto-para-o-uso e imediatamente disponível, do tipo prometido pelos programas de software, que entram e saem das prateleiras das lojas em uma sucessão sempre acelerada, parece muito mais atraente. (Bauman, 2002, p. 49).

$\mathrm{Na}$ perspectiva de Bauman não é de interesse comum atribuir importância ao conhecimento duradouro da experiência, já que a referência de conhecimento consiste na relevância momentânea do assunto, onde importa a informação atual, cuja principal característica é ser "eminentemente descartável, bom apenas até segunda ordem e só temporariamente útil" (Bauman, 2007, p. 154). Esta nova dinâmica, pautada na informação fugaz, substitui a autoridade do conhecimento pelas seduções do mercado de consumo, dificultando proposta educacional associada à escola tradicional. A educação atual é desejável e valorizada como mercadoria que, dispensada da formação moral, se torna um produto informativo, comprometido com o ensinamento da técnica e com o atendimento ao cliente, "não há sanções contra os que saem da linha e se recusam a prestar atenção - a não ser o horror de perder uma experiência que os outros (tantos outros!) prezam e desfrutam" (Bauman, 2003, p. 43). Num sistema social pautado unicamente na informação descartável:

um bit de informação é caçado por outro antes mesmo que possa ser absorvido, e, uma vez que eles não são assimilados, não podem ser conectados a uma cadeia de eventos significativa. Cada evento deve assim "sobreviver" por conta própria, e o senso de totalidade é deixado para trás pelos competidores já no início da caçada (Bauman, 2000, p. 100 , grifo do autor).

Baudrillard assume uma postura de alerta sobre o desenvolvimento tecnológico. Entende que a sociedade tecnológica se constitui pela comunicação virtual através das tecnologias em massa de comunicação e informação - TICs. Tais sistemas tecnológicos influenciam nossa percepção de mundo produzindo ilusões que se opõem ao que é real, culminando num processo autodestrutivo que resulta numa implosão do social. No processo de comunicação virtual se abdica da prática racional de absorção de conteúdo e prevalece a sensação diante do espetáculo da informação, onde o que importa é o consumo da forma e não o conteúdo. "Assim a informação dissolve o sentido e dissolve o social numa espécie de nebulosa voltada, não de todo a um aumento de inovação, muito pelo contrário, à entropia" (Baudrillard, 1991, p. 106). Essa postura própria das sociedades tecnológicas inviabiliza a circulação social do sentido promovendo o esvaziamento do real, tendo como principal característica a indiferença social e o egoísmo.

O autor sinaliza como característica própria do virtual a propagação de uma perspectiva autorreferente, um processo que não é mediado pelo reconhecimento da diferença, onde tudo se torna homogêneo e alienante. Na perspectiva do autor, a realidade virtual ou simulacro é aquela que conduz de forma unidirecional as massas, impossibilitando a experiência real que 
consiste na capacidade de vivenciar e reconhecer o diferente, o outro (Baudrillard, 1997). Nesse sentido, o virtual enquanto mecanismo de afirmação da indiferença promove o egoísmo e a implosão do social, no entendimento do social como espaço público mediado pela multiplicidade e pelo reconhecimento do outro. Entendendo como virtual um tipo de realidade que se fecha sobre si mesmo, autorreferente, o autor afirma, "a potência do virtual nada mais é do que o próprio virtual. Por isso pode intensificar-se de maneira alucinante e, sempre mais longe do mundo dito real, perder ela mesma todo princípio de realidade" (Baudrillard, 1997, p. 26).

Lévy (2005, p. 11), muito citado na educação, entente de outro modo. Aponta para uma evolução cultural em andamento e "apesar de seus inegáveis aspectos sombrios e terríveis", essa mudança cultural é um fenômeno próprio da condição humana, ampliando a criatividade e a percepção de mundo. Aponta para um possível equívoco entre aqueles que entendem a tecnologia como causa e a cultura como vítima de seus efeitos, já que tecnologia e cultura estão numa relação de práxis, produzindo mutuamente novas possibilidades. Pondera que a loucura e a violência do nosso tempo não são determinadas pela tecnologia, mas uma consequência da falta de compreensão sobre o que é o virtual e os processos tecnológicos. "Antes de temê-la, condená-la ou lança-la às cegas, proponho que se faça o esforço de apreender, de pensar, de compreender em toda a sua amplitude a virtualização" (Lévy, 2005, p. 12). Lévy (2005) considera como perspectiva tradicional o estágio social onde o conhecimento era duradouro, contemplativo e centrado nos fundamentos. Na atualidade, entende-se que o conhecimento é transformado em fluxo, algo móvel e imaterial, que produz operações eficazes onde o próprio conhecimento é uma operação.

Para o autor a característica imaterial do conhecimento e da informação estimula a propagação e a colaboração entre saberes, uma vez que "consumí-los não os destrói e cedê-los não faz com que sejam perdidos" (Lévy, 2005, p. 55). O livre acesso à informação permite que o conhecimento não se restrinja a certos grupos, "não é mais uma casta de especialistas, mas a grande massa das pessoas que são levadas a aprender, transmitir e produzir conhecimentos de maneira cooperativa em sua atividade cotidiana" (Lévy, 2005, p. 55). Este seria o momento de orientar a evolução em curso uma vez que as alternativas são:

Ou o ciberespaço reproduzirá o mediático, o espetacular, o consumo de informação mercantil e a exclusão numa escala ainda mais gigantesca que hoje. Esta é, a grosso modo, a tendência natural das "supervias da informação" ou da "televisão interativa". Ou acompanhamos as tendências mais positivas da evolução em curso e criamos um projeto de civilização (Lévy, 2005, p. 118).

Castells (2005) avalia que o dilema levantado por algumas pessoas ao considerar que a sociedade é determinada pela tecnologia não faz sentido, "dado que a tecnologia é a sociedade, e a sociedade não pode ser entendida ou representada sem suas ferramentas tecnológicas" (Castells, 2005, p. 43). Salienta que a relação entre tecnologia e sociedade deve ser entendida considerando o papel mediador do Estado, cuja organização é um fator decisivo na interrupção, promoção ou liberação de uma dada inovação tecnológica. Para Castells a produção de tecnologia é um fenômeno antropológico e a evolução social é complexa e não deve, 
equivocadamente, ser equacionada apenas pelo viés tecnológico. Sobre o egocentrismo crescente $o$ autor entende que:

\begin{abstract}
a identidade está se tornando a principal e, às vezes, única fonte de significado em um período histórico caracterizado pela ampla desestruturação das organizações, deslegitimação das instituições, enfraquecimento de importantes movimentos sociais e expressões culturais efêmeras. Cada vez mais, as pessoas organizam seu significado não em torno do que fazem, mas com base no que elas são ou acreditam que são. Nessa condição de esquizofrenia estrutural entre a função e o significado, os padrões de comunicação social ficam sob tensão crescente. cada vez mais difíceis de compartilhar (Castells, 2005, p. 41).
\end{abstract}

Castells defende a importância da racionalidade e a possibilidade de recorrer à razão como meio para a compreensão deste novo tempo, onde "a suposição implícita é a aceitação da total individualização do comportamento e da impotência da sociedade ante seu destino" (Castells, 2005, p. 42). Enquanto Postman (1994), Bauman (2007) e Baudrillard (1991) entendem que a tecnologia produz uma influência problemática, capaz de diluir a consciência social promovendo um individualismo exagerado e alienante, Lévy (2005) e Castells (2005) recolocam a questão apontando que é a falta de senso crítico que promove um relacionamento problemático com a tecnologia, levando à diluição da consciência social e ao estímulo do individualismo exagerado.

Embora esses autores discordem quanto ao agente motivador dos problemas sociais, cada um ao seu modo, entende que vivemos em uma época de mudanças, onde a tendência está na manifestação do pensamento unilateral e no culto ao individualismo, sinalizam a importância de mediações através da política, do estado e da escola, no intuito de resgatar ou construir um projeto de sociedade e de indivíduo. Para eles é necessário o aperfeiçoamento coletivo do senso crítico como meio de estimulação de uma consciência social e tecnológica.

É nesta direção que Fantin e Girardello (2009) sinalizam. As autoras defendem a importância de ambientes educacionais capazes de promover inclusão digital, de forma a "favorecer a formação crítica de cidadãos, não apenas de usuários" (Fantin; Girardello, 2009, p. 78), ressaltando a necessidade de uma perspectiva educacional que contemple dimensões sociais, intelectuais, culturais e tecnológicas, onde a construção de cidadania ocorre pautada numa real participação de crianças, jovens e adultos na cultura.

Segundo Aranha favorecer a formação crítica de cidadãos demanda, por parte dos envolvidos, uma clareza na concepção de sociedade e do indivíduo que se deseja construir, sendo necessário direcionar esforços e responder "Que tipo de pessoa se quer formar? Para qual sociedade?" (2006, p. 33). Na perspectiva de Carraher (1983) uma postura pautada pelo senso crítico "implica em adotar perspectivas múltiplas para examinar as questões sob várias óticas" (2002, p. XXI) sendo que uma postura baseada em um pensamento unilateral dilui o potencial do senso crítico na medida em que impede o uso de múltiplas perspectivas. Assim, Aranha e Carraher entendem que o processo de desenvolvimento e prática do senso crítico demanda contextualização, direcionamento e aplicação sistemática de regras que atuam como mecanismos de orientação do pensamento. 
Para Wittgenstein (2005) a constituição das regras de orientação do pensamento ocorre na linguagem e não deve ser individual, autorreferente. Segundo o autor, para que ocorra um pensamento consistente é necessário que os parâmetros de referência sejam sociais, públicos. A perspectiva de um modelo autorreferente implica em um individualismo sem mediação, onde a pessoa se refere a si mesma, culto ao "eu", como parâmetro único de percepção e entendimento do mundo. Sobre a impossibilidade do pensamento constituído numa postura autorreferente, o autor pondera:

Suponhamos que cada um tivesse uma caixa e que dentro dela houvesse algo que chamamos de 'besouro'. Ninguém pode olhar dentro da caixa do outro; e cada um diz que sabe o que é um besouro apenas por olhar o seu besouro. Poderia ser que cada um tivesse algo diferente em sua caixa. (Wittgenstein, 2005, p.137).

Sob este aspecto, a percepção individual enquanto postura de isolamento social oferece dificuldades para o funcionamento do ambiente compartilhado e do desenvolvimento da sociedade como um todo, podendo promover desentendimentos e diluição do senso crítico.

Além da popularização de uma postura autorreferente e da aplicação de um raciocínio binário, outro evento que também parece oferecer dificuldade ao desenvolvimento social, promovendo confusões e diminuição do senso crítico, consiste na ausência de regras que orientam o pensamento. Nesta direção aponta Murcho (1998), filósofo português que leciona na Universidade Federal de Ouro Preto, MG, sua produção intelectual inclui reflexões sobre a lógica na educação e construção do pensamento. Segundo Murcho é a lógica que, "entre outras coisas, estabelece as normas que as pessoas têm de cumprir se desejam realmente alcançar o raciocínio correto ou válido" (1998, p. 390). Murcho se refere ao uso da lógica em um sentido amplo e defende o uso da lógica informal uma vez que esta se ocupa do estudo de todos os tipos de argumentos, permitindo melhor se entender as questões implicadas numa dada argumentação. Entendendo que a argumentação está presente num processo de negociação e que um bom argumento é persuasivo sobre uma dada possibilidade e ainda, que toda negociação depende da aceitação dos argumentos entre os interlocutores, pois para que

\footnotetext{
uma inferência seja boa é apenas necessário que seja um argumento válido. Mas um bom argumento é mais do que meramente válido: é um argumento persuasivo. A plausibilidade das premissas é relativa ao estado cognitivo do agente e não é discreta, mas sim contínua. A solidez de um argumento (a conjunção da verdade com a validade) é independente dos agentes cognitivos. Mas os agentes cognitivos não são omniscientes e perante cada premissa ou conclusão têm de avaliar como mais ou menos plausível, à luz do que julgam saber em geral. Assim, um argumento pode ser bom ou mau, melhor ou pior, mais ou menos forte ou cogente, apesar de ser sólido. Um argumento bom, forte ou cogente é um argumento que além de sólido tem premissas mais plausíveis do que a conclusão. (Murcho, 2010, s/p.)
}

A perspectiva de plausibilidade encontrada em Murcho (2010) recoloca nos termos da lógica informal a subjetividade como algo próprio do gestor da ação, tomada de decisão, onde o verdadeiro ou falso é dependente de um dado contexto em conformidade com tendências interpretativas influenciadas pelas interações sociais. O evento da autorreferência, do raciocínio 
binário e da ausência de análise lógica parece estar relacionado a um círculo vicioso que estimula o outro promovendo o desentendimento, dificultando o papel da escola na formação crítica de cidadãos. Entendendo que na atualidade o isolamento social, individualismo exagerado, se constitui numa tendência crescente de comportamento que compromete o funcionamento do espaço público, ou ainda, que a postura binária se populariza fragmentando o conhecimento e promovendo desentendimentos e rivalidades também entre os educadores, pode ser difícil responder, "como favorecer a formação crítica de cidadãos?" principalmente se considerarmos que é necessário um senso de unidade com claro direcionamento e mediação pública, algo defendido por alguns como ultrapassado.

Nesse sentido, algumas observações de Postman (1994), Bauman (2007), Baudrillard (1991), Lévy (2005) e Castells (2005) parecem complementares uma vez que, na ausência de outro mecanismo de mediação para a formação crítica de cidadãos, o raciocínio tecnológico se torna o mediador disponível através do contato cotidiano das pessoas com a tecnologia. A complementariedade nesses autores está na possibilidade de um movimento circular onde, segundo Lévy (2005) e Castells (2005) o enfraquecimento do senso crítico dificulta o entendimento claro dos efeitos da tecnologia, promovendo na perspectiva de Postman (1994), Bauman (2007) e Baudrillard (1991), uma relação com a tecnologia que potencializa um tipo de raciocínio tecnológico capaz de enfraquecer o senso crítico.

O raciocínio tecnológico cotidiano diagnostica defeitos e conserta equipamentos, ele parece promover dificuldades quando aplicado em questões do comportamento humano, especialmente devido à sua característica simplificadora e excludente. Nesta perspectiva existe o risco interpretativo de considerar o humano como um tipo de objeto cujo sentido existencial é destinado unicamente a atender um dado conjunto de utilidades, um tipo de utilitarismo que iguala os humanos e as máquinas tanto em valor como em destino, onde ambos, máquinas e humanos, podem ser programados, usados, consertados e descartados.

\section{UM MERGULHO NO PRONATEC: PARA SUPERAR AS CONTRADIÇÕES}

No âmbito da capacitação técnica, ganha destaque o Programa Nacional de Acesso ao Ensino Técnico e Emprego (Pronatec), declarado pela presidente Dilma Rousseff em maio de 2014 no blog do planalto como "um dos pilares da política educacional". Vitrine de campanha nas eleições de 2014, o Pronatec, segundo a imprensa, realizou mais de 5,7 milhões de matrículas e a estimativa é de oito milhões até 2015 (Blog do Planalto, 2014). Em junho de 2014, foi lançada uma nova modalidade do Pronatec, focada nos direitos humanos com o objetivo de atender setores carentes da sociedade. Em 26 de novembro de 2014, o Diário Oficial da União divulgou as 229 regras desta nova modalidade dividida em três categorias, o "Pronatec viver sem limite" destinado a pessoas com deficiência, o "Pronatec Sinase" que atua na capacitação profissional de adolescentes que estão em medida socioeducativa e o "Pronatec Pop Rua" destinado a atender pessoas em situação de rua (Brasil, 2014). Dados do MEC apontam que $40 \%$ dos usuários do Pronatec convencional são alunos de baixa renda, registrados no Cadastro Único de Programa social e $60 \%$ do total de usuários são jovens que estão na faixa dos 19 aos 24 anos. O Pronatec inicia em 2015 com um orçamento de 14 bilhões para investimentos em 12 milhões de vagas em 220 cursos técnicos de nível médio e 646 cursos de qualificação (PDE/Pronatec, 2011). 
O Programa Nacional de Ensino Técnico e Emprego (Pronatec) começou a se popularizar no final de 2013, tendo como proposta facilitar a qualificação profissional entre aqueles que concluíram o ensino médio e buscam por melhores oportunidades de trabalho. Segundo esclarece o MEC, o Pronatec tem por objetivo:

\begin{abstract}
Expandir, interiorizar e democratizar a oferta de cursos de educação profissional técnica de nível médio e de cursos de formação inicial e continuada ou qualificação profissional presencial e a distância; construir, reformar e ampliar as escolas que ofertam educação profissional e tecnológica nas redes estaduais; aumentar as oportunidades educacionais aos trabalhadores por meio de cursos de formação inicial e continuada ou qualificação profissional; aumentar a quantidade de recursos pedagógicos para apoiar a oferta de educação profissional e tecnológica; melhorar a qualidade do ensino médio (MEC, 2011, $s / p$.$) .$
\end{abstract}

Sendo um programa relativamente novo existe uma série de desafios ainda aguardando superação. A falta de orientação clara para a população tem proporcionado confusões, como inscrições de alunos em cursos que não são realmente de interesse, participação em disciplinas sem os requisitos necessários para o adequado entendimento do conteúdo, além da falta de planejamento, por parte do aluno, para conciliar o tempo de estudo com o trabalho. Esses problemas são apontados pelos alunos como principais causas de desistência, chegando-se numa média de 60\% de evasão em algumas escolas (Costa, 2014).

Em outubro de 2014, o primeiro autor assumiu turmas no curso técnico de informática do Pronatec. Ao total, ingressou em três escolas, uma em Alvorada, outra em Viamão e também uma em Porto Alegre. Acabou exercendo atividade de professor nos três turnos, manhã, tarde e noite. Em novembro de 2014 foi efetivado em uma escola em Porto Alegre, na qual continua lecionando sobre lógica de programação na modalidade Pronatec até o presente momento. $O$ ambiente em sala de aula também impõe ao professor o desafio de cumprir o currículo da disciplina conciliando as particularidades de cada pessoa, sendo comum participar da mesma turma pessoas sem o mínimo de conhecimento básico (pré-requisito), pessoas sem motivação na capacitação ofertada, pessoas com dificuldades cognitivas e também pessoas com os mais variados interesses, sendo alguns distantes do objetivo do curso escolhido. Em uma das turmas Pronatec que participou como professor de lógica de programação, em um curso técnico para o desenvolvimento de sistemas computacionais, o grupo é configurado por quatro pessoas idosas que se inscreveram após deduzir que iriam aprender a manusear o computador no estilo "informática para a terceira idade", três pessoas com aparente dificuldade cognitiva, sendo que, em ambos os casos, nenhum deles possui computador ou sequer havia usado este recurso tecnológico antes de se inscrever no curso. Nesta mesma turma participam dois universitários que frequentam, o segundo semestre, do curso de graduação em ciência da computação, seis alunos que concluíram o ensino médio recentemente e um aluno que está concluindo o técnico em mecatrônica.

Nesta turma a diferença entre os 16 participantes da disciplina demanda uma dinâmica diferenciada para cada aluno, assim como nas outras turmas, impossibilitando uma prática tradicional baseada em atividade generalizada. Enquanto alguns precisam descobrir como ligar o computador e o que significam as luzinhas que piscam, outros dominam a tecnologia e anseiam por conhecimentos mais avançados, todos em um mesmo espaço de convivência e na mesma 
sala de aula. Neste ambiente diversificado surgiu a oportunidade de observar e interagir com ocorrências envolvendo tanto professores como alunos. Além das dificuldades com a aplicação do conteúdo, que demanda um maior esforço do professor, chamou a atenção os problemas de relacionamento e o tipo de mediação praticado por alguns professores.

Na segunda semana de atividade foi assumida uma turma cujo professor apresentou problemas de estresse e precisou ser afastado. Fiquei surpreso com o modelo do rigor disciplinar: alunos com 10 minutos de atraso recebiam falta, o caderno de chamada possuía anexado, e bem organizado, um conjunto de registros que identificava cada aluno em um grupo de ocorrências como, por exemplo, quem cochichava, dormia ou apresentava atitude em aula passível de correção. Após assumir a turma e ter a oportunidade de conviver com esses alunos observou-se que alguns regularmente se atrasavam por não possuírem recursos para se deslocarem, se matricularam em um curso que, equivocadamente, acreditaram fornecer vale transporte e auxílio refeição, outros se atrasavam por possuírem trabalhos informais com horários diferenciados.

A aplicação de um modelo disciplinar rigoroso provocou conflitos e revolta em alguns alunos gerando, por parte daquela turma, uma combinação para dificultar a dinâmica de trabalho do professor. A crise de estresse parece ter sido uma consequência da resposta sistemática organizada pelos alunos em oposição ao rigor disciplinar entendido como injusto pela turma. Em outra turma, o professor enviou um e-mail perguntando se seria possível assumir a disciplina, já que ele estava arrependido por aceitar o trabalho, esclareceu:

Eu só aceitei pq amo lógica e gostei da escola, mas temos que parar de abrir espaço de choradeira, eles tem grupo de whats e passam questionando tudo, mas pode verificar na chamada estão com muitas faltas e pouco comprometimento. Essa é a turma mais desanimada que já dei aula. .td reclamam... aula teórica, didática, trabalho em grupo, participação em aula. Se você tem disponibilidade para assumir a turma seria perfeito (correspondência eletrônica com colega professor da mesma escola).

Do período de ingresso na escola até a escrita deste artigo, o primeiro autor ocupou-se de cinco turmas do Pronatec com um total de duas disciplinas: Lógica de Programação e Arquitetura de Computadores. Em todas as turmas os alunos se mostraram queixosos e questionadores, geralmente apresentaram questões pertinentes e relacionadas com a falta de adequação da escola para acolher a realidade deles, além das frustrações com as promessas efetuadas na hora da "venda" do curso. Também surgiram questionamentos sobre a qualidade da dinâmica e conteúdo apresentado. Um exemplo foi a queixa de alguns alunos sobre a reprovação por faltas e a necessidade de atestado para justificá-las. A pergunta da maioria dos alunos frente à exigência de atestado foi sobre quem atesta quando o trabalho informal origina a falta, como os motoboys irregulares, vendedores ambulantes, ou ainda, pela falta de dinheiro para alimentação ou transporte etc. Na percepção desses alunos a escola deveria incluir não apenas a doença e o trabalho formal como emergência suficiente para justificar falta.

Outro questionamento foi sobre como e quais os motivos para a proposição desta ou daquela atividade e, uma vez entendida a proposta, perguntavam pelos critérios para avaliarem o meu trabalho, queriam saber como mensurar se o que estou propondo chega ao resultado esperado, contemplando a impossibilidade de esforço por parte deles, uma vez que a vida não 
Ihes permitia dedicação para os assuntos da escola. Escutou-se em mais de uma ocasião o relato de alguns alunos sobre como percebiam a escola e a oportunidade de se capacitarem pelo Pronatec, geralmente em um tom de decepção esclareceram:

Ninguém dá nada, se o governo nos paga o curso é porque precisam fazer isso pra ganhar alguma coisa usando a gente, sempre que faltamos na aula a escola liga no mesmo dia, se eu não venho eles perdem dinheiro, dai ficam implorando para nós não faltarmos. Claro que eu vou me esforçar na medida do possível, mas são eles que precisam de mim, nem computador eu tenho e trabalho 16 horas por dia, eles que achem uma maneira de me ensinar, se não, não ganham dinheiro. Eu vim aqui porque disseram que iam me ensinar uma profissão, minha parte eu fiz, estou aqui.

Esta é uma característica interessante do Pronatec, um projeto relativamente novo, que abriu uma grande variedade de possibilidades de capacitação firmando parceria com escolas privadas. No entanto, na dinâmica do modelo privado os vendedores precisam cumprir cotas de vendas, conseguindo uma dada quantidade de alunos matriculados. Com a necessidade de atender às metas de vendas surgem promessas e orientações equivocadas, estimulando o ingresso de alunos sem disponibilidade de tempo, afinidade com o curso etc. Na promessa de alguns vendedores, tudo será resolvido pelos capacitados professores.

Com algumas turmas, onde a maioria dos alunos se matriculou por impulso, motivados pelo discurso comercial, surgiram problemas como alta evasão e falta de comprometimento. Com o amadurecimento do Pronatec esses problemas provavelmente serão mais bem equacionados e parecem próprios de um sistema em adaptação, no entanto, não é incomum alguns professores e alunos polarizarem a questão sem considerar as consequências e limites de interação do modelo ofertado. Das turmas em contato apenas cerca de um terço dos alunos possuíam interesse e motivação relacionados com o aprendizado e domínio da técnica de programação, os demais alunos ingressaram no curso por motivos diversos, que não contemplaram a expectativa de conclusão do curso.

Em parte, parece que a própria configuração do ambiente e a dificuldade de relacionamento entre professores, alunos e escola, proporcionaram a condição de possibilidade para o pouco comprometimento dos alunos. No intervalo, na sala de professores, diariamente ocorriam desabafos de outros colegas sobre atritos acalorados em sala de aula, motivados pela falta de obediência dos alunos, estes por sua vez, reclamavam da falta de respeito dos professores.

Durante o período de acompanhamento da realidade cotidiana da sala de aula foi possível observar que os conflitos de relacionamentos foram proporcionais à intensidade de um tipo de rigor disciplinar imposto pelo professor ou escola. Dos fenômenos vivenciados até o presente momento no ambiente escolar se destacou a ausência de disponibilidade para a negociação como principal fonte de conflitos entre alguns professores, alunos e escolas.

Algo interessante na negociação é o fato desta ocorrer entre necessitados que se encontram num momento de igualdade, cada um necessita de algo ao mesmo tempo em que possui algo para oferecer, trocar. Sob essa perspectiva o agente regulador em uma negociação 
parte do reconhecimento da necessidade que se manifesta no outro como algo espontâneo e resistente à indiferença do rigor disciplinar e sua autoridade.

O termo espontâneo é abordado aqui como algo que, independente da vontade do indivíduo, afeta o discernimento, influenciando a percepção e produzindo um tipo de conhecimento pautado na vivência das relações humanas, onde a interpretação de um dado fenômeno é construída em coerência com a necessidade que afeta uma pessoa ou grupo.

Ao colocar a espontaneidade do afeto como um agente regulador das relações sociais e do próprio discurso na educação, parece fazer sentido, o agitado ambiente escolar, o excesso de binarismos e concorrências que dificultam a colaboração e o diálogo no meio educacional.

Ao ficar diretamente implicado no ambiente de sala de aula foi possível observar que as tendências interpretativas, percepções de mundo, possuem forte influência da espontaneidade do afeto, onde o saber formal ocupa um espaço secundário na tomada de decisão, mesmo quando amplamente divulgado na forma de discursos ou propagação de modismos teóricos. Nesse sentido, a tomada de decisão é geralmente manifestada no choque entre necessidades e emergências do cotidiano, certezas do afeto, contrariando em ação os discursos proferidos, conhecimentos.

\section{CONSIDERAÇÕES FINAIS}

Enquanto no ambiente de produção tecnológica se faz necessária a construção de uma percepção que possibilite a manutenção, invenção e fabricação de máquinas e seus derivados, na educação, a centralidade é a valorização da condição humana, na legitimidade do gestor da ação, nas relações sociais e suas consequências. Admitindo que cada área do saber se ocupe de um limitado conjunto de aspectos da vida, como uma contribuição específica à organização social, se torna coerente a existência de diferentes crenças, estratégias de raciocínio e percepções. Nesse sentido, o papel da computação no ambiente educacional é polêmico. Para alguns, o raciocínio tecnológico é percebido como fenômeno que promove egoísmos e indiferenças, enfraquecendo as relações sociais, enquanto outros enxergam na tecnologia a facilidade para o surgimento de um comportamento mais colaborativo, proporcionando novas formas criativas de interação social.

Mesmo com a popularização de diversas teorias, incluindo as da complexidade, que defendem a importância de se considerar a condição humana como algo integral, indivisível, onde uma postura pautada na estratégia binária de percepções não é recomendada no âmbito educacional, surgem diariamente, em considerável número, adeptos de polarizações e determinismos, reafirmando a superioridade da razão instrumental como o melhor caminho para as questões da educação. Sob este aspecto parece ocorrer um equívoco, em especial quanto ao papel de cada área do saber e sua intencionalidade. É próprio, e talvez necessário no raciocínio tecnológico, adotar como percepção de mundo um tipo de determinismo material, como o determinismo orgânico, linguístico, neurológico, entre outros, onde o detentor da técnica, motivado pela certeza do determinismo, exerce sua capacidade de manipulação, impondo sua autoridade intelectual ao objeto, matéria. 
Ao considerar a espontaneidade do afeto como principal fenômeno motivador do comportamento humano e ponto de partida para pensar a educação, perde sentido o uso de certezas e estratégias deterministas de análises próprias da engenharia, ganha força uma perspectiva centrada no reconhecimento da pessoa enquanto gestora da ação, numa perspectiva que admite um tipo de relativismo moderado. Esta perspectiva, embora mais bem adequada para se pensar educação, também apresenta problemas quando equivocadamente, por conta de um ou outro excesso, incentiva um modelo permissivo na medida em que a espontaneidade do afeto é recebida como fenômeno que isenta de responsabilidade o gestor da ação. No entanto, ao invés de certezas, a proposta de assumir riscos de forma consciente, identificando limites, tem se mostrado um melhor caminho no âmbito das ciências humanas e da aprendizagem, em especial, se concordarmos que a garantia da certeza só é possível no trato com objetos, uma vez que resulta num tipo de determinismo que impossibilita o espontâneo, a criatividade e a autonomia, requisitos para se pensar a educação.

Foi no experimento da sala de aula, frente a frente com as questões do cotidiano educacional e seus dilemas, que ficou claro a diferença entre a lógica dos objetos construídos pelo conhecimento de engenharia e a importância da rebeldia, do espontâneo e da autonomia do gestor da ação nas relações sociais e no processo de aprendizagem. A falta de uma percepção clara sobre a intencionalidade da educação enquanto instituição, os excessos na valorização de modelos técnico-científicos e a prática de um tipo de autoritarismo próprio das engenharias, além de uma interpretação equivocada quanto ao lugar de outras áreas do saber e suas intencionalidades, parecem colaborar para o acolhimento de um conjunto de influências que confundem uma parcela dos profissionais em educação e demais envolvidos, dificultando uma interdisciplinaridade coerente e um direcionamento adequado sobre o papel da escola e de seus participantes.

No entanto, se tal equívoco ocorre, é possível sugerir que falta condição de possibilidade para uma prática reflexiva, como a elevada carga horária na jornada de trabalho em um cotidiano repleto de emergências e estresse, ausência de um espaço de diálogo e incentivo à reflexão, baixos salários, além da falta de reconhecimento social que parece despertar em alguns educadores a necessidade de transformar a educação em uma das engenharias, tipo de ciências enquanto área do saber com elevado reconhecimento social.

Ao colocar a espontaneidade do afeto no centro das questões sobre educação é possível sugerir que a educação não opera adequadamente quando seus representantes autoritariamente destituem de legitimidade o saber do sujeito da ação, que é indivisível de suas narrativas e relações sociais, em outras palavras, diferente das engenharias, a educação não trata apenas de explicar como as coisas funcionam e determinar sua ordem a partir de um único olhar, seja ele científico ou não, mas de promover uma percepção capaz de acolher múltiplas possibilidades, onde "não vemos as coisas como são, mas como somos" (Demo, 2012, p. 1). É no caminho da negociação coerente, do exercício hermenêutico, que a educação talvez encontre um lugar próprio, menos confuso, um modo de existir mais bem conectado com sua própria intencionalidade.

\section{REFERÊNCIAS}

Aranha, M. L. de A. (2006). Filosofia da Educação. São Paulo: Moderna. 
Baudrillard, J. (1998). Selected Writings edited by Poster, Mark, Stanford University Press, California.

. (1991). Simulacros e Simulações. Lisboa: Relógio D’Água.

. (1997). Tela Total: Mito-Ironias da Era do Virtual e da Imagem. Porto Alegre.

Bauman, Z. (2003). Comunidade: a busca por segurança no mundo atual. Rio de Janeiro: Jorge Zahar.

. (2002). Desafios educacionais da modernidade líquida. Tempo Brasileiro, 148, 41-58.

. (1997). Ética pós-moderna. São Paulo: Paulus.

. (2000). Os livros no diálogo global das culturas. Tempo Brasileiro, 142, 87-101.

. (2007). Vida líquida. Rio de Janeiro: Jorge Zahar.

Blog do Planalto. (2014). Dilma: Pronatec é um dos pilares da política educacional. Recuperado de http://blog.planalto.gov.br/dilma-pronatec-e-um-dos-pilares-da-politica-educacional/

Brasil. (1996). Lei № 9.394/1996. Estabelece as diretrizes e bases da educação nacional. Recuperado de: http://www.planalto.gov.br/ccivil_03/leis/l9394.htm

Brasil. (2012). Ministério da Educação. Número de brasileiros com graduação cresce 109,83\% em 10 anos. Recuperado de: http://portal.mec.gov.br/index.php?option=com_content\&view=article\&id=17725

Brasil. (2014) Secretaria de Direitos Humanos da Presidência da República. Pronatec Direitos Humanos amplia políticas de qualificação profissional para pessoas com deficiência Recuperado de: http://www.sdh.gov.br/noticias/2014/novembro/pronatec-direitoshumanos-amplia-politicas-de-qualificacao-profissional-para-pessoas-com-deficiencia.

Demo, P. (2012). Não Vemos as coisas como são, mas como somos. Fronteira da educação, 1(1), 1-23, Recuperado de: http://fronteirasdaeducacao.org/index.php/fronteiras/article/download/7/11

Fantin, M.; Girardello, G. (2009). Diante do abismo digital: mídia-educação e mediações culturais. Perspectiva, 27(1), 69-96.

FNDE - Fundo Nacional de Desenvolvimento da Educação. Tabletes. (2012). Programas/Prolnfo. Recuperado de: http://www.fnde.gov.br/programas/programa-nacional-de-tecnologiaeducacional-proinfo/proinfo-tablets.

G1 - globo.com. (2013). Brasil evolui, mas segue nas últimas posições em ranking de educação. Recuperado de: http://g1.globo.com/educacao/noticia/2013/12/brasil-evolui-mas-seguenas-ultimas-posicoes-em-ranking-de-educacao.html.

INEP - Instituto Nacional de Estudos e Pesquisas Educacionais Anísio Teixeira. (2011). Indicadores Financeiros Educacionais. Recuperado de: http://portal.inep.gov.br/indicadoresfinanceiros-educacionais.

LÉVY, P. (2005). O que é o Virtual? São Paulo: 34.

- (1993). As tecnologias da inteligência: o futuro do pensamento na era da informática. São Paulo: Editora 34.

.(2000). Cibercultura. 2. ed. São Paulo: Editora 34. 
MEC, Ministério da Educação e Cultura. (2011). Objetivos e iniciativas. Recuperado de: http://pronatec.mec.gov.br/institucional-90037/objetivos-e-iniciativas.

Moraes, M. C. (1997). O paradigma educacional emergente. 13. ed. Campinas: Papirus.

Murcho, D. (2011). Lógica Informal. Recuperado de: http://criticanarede.com/logicainformal.html.

PDE/Pronatec - Programa Nacional de Acesso ao Ensino Técnico e Emprego. (2011.). Como se desenvolve o Pronatec. Recuperado de: http://vestibular.brasilescola.com/bolsasestudo/como-se-desenvolve-pronatec.htm

Postman, N. (2002). O fim da educação. Rio de Janeiro: Graphia.

_. (1994). Tecnopólio: a rendição da cultura à tecnologia. São Paulo: Nobel.

Pretto, N.; Pinto, C. da C. (2006). Tecnologias e novas educações. Revista Brasileira de Educação, 11(31), 19-30.

UOL - Educação. (2014). Pronatec é um caça-níquel para redes privadas, afirma especialista. Recuperado de: http://educacao.uol.com.br/noticias/2014/06/30/pronatec-e-um-cacaniquel-para-redes-privadas-diz-especialistas.htm.

UOL Educação. (2013). Brasil tem 3a maior taxa de evasão escolar entre 100 países, diz Pnud. Recuperado de: http://www.todospelaeducacao.org.br/educacao-namidia/indice/26226/brasil-tem-3-maior-taxa-de-evasao-escolar-entre-100-paises-diz-pnud.

Wittgenstein, L. (2005). Investigações Filosóficas. Petrópolis, RJ: Vozes. 